\title{
The Biological Effect and Clinical Application of Long Noncoding RNAs in Colorectal Cancer
}

\author{
Zhenqiang Sun Jinbo Liu Chen Chen Quanbo Zhou Shuaixi Yang \\ Guixian Wang Junmin Song Zhen Li Zhiyong Zhang Jizhong Xu \\ Xiantao Sun Yuan Chang Weitang Yuan
}

Department of Anorectal Surgery, The First Affiliated Hospital of Zhengzhou University, Zhengzhou, Henan, China

\author{
Key Words \\ LncRNAs • Colorectal cancer • Tumorigenesis • Progression
}

\begin{abstract}
Colorectal cancer (CRC) is one of the most common malignancies in the world. Easier recurrence and metastasis is the main cause of mortality in CRC patients, and the markers applied for diagnosis and treatment of CRC is still urgently needed to early diagnose and evaluate therapeutic effect. Long noncoding RNA (IncRNA) is a class of noncoding RNA that the length is more than 200 nucleotides. With the development of sequencing technique about transcriptome, increasing IncRNAs are focused on their function and mechanism related to the nosogenesis and pathology of CRC. Recent studies report that IncRNAs acted as crucial role in CRC and could be as biomarker for CRC diagnosis and treatment. In this review, we display the regulation of IncRNA by interacting with DNA, RNA and protein and highlight the double role of IncRNAs as oncogene or anti-tumor gene involved in Wnt signaling pathway, p53 signaling pathway or others to be an regulator in CRC development. Lastly, we discuss some new finding of IncRNAs, especially IncRNA in exosome, which could be as potential markers for diagnosis and treatment of CRC in future.

(C) 2018 The Author(s)

Published by S. Karger AG, Basel
\end{abstract}

\section{Introduction}

Because of colorectal cancer (CRC) easily recurrence and metastasis, about 1.36 million new cases and 694, 000 death cases were reported in every year [1]. In China, morbidity of $\mathrm{CRC}$ is on progressively increasing level and its mortality ranks the fifth of cancer-correlative death $[2,3]$. Fundamentally, CRC is closely linked with dietary habit, genetic factor and disease factor, such as high fat and protein diet, family medical history, and chronic inflammation.

Z. Sun, J. Liu and C. Chen contributed equally to this work.

Zhenqiang Sun, Jinbo Liu and Weitang Yuan
Department of Anorectal Surgery, The First Affiliated Hospital of Zhengzhou University, Zhengzhou, Henan (China)

E-Mail zqsun82@csu.edu.cn, 1999liujb@163.com, yuanweitang@zzu.edu.cn 
Effect of CRC early screening showed high survival rate and low mortality in age of more 50 years old [4]. Therefore, it is very emergency to study pathogenesis of CRC and find one or more efficient biotargets to improve the survival quality of CRC patients $[5,6]$.

A previous study of human genome displayed that only 1.5\%-2.0\% genes of the whole genome were protein-coding genes (PCG), most of the others were performed transcription process and produced non-coding RNA (ncRNA) [7, 8]. LncRNAs, chiefly form by RNA polymerase II, are a class of ncRNAs with a length of more than 200nt and has no open reading frame (ORF) $[9,10]$. Due to its long nucleotide chain and intricate secondary structure, lncRNAs could combine with protein by its multiple binding sites or specifically act on DNA or RNA by base pairing summarizing RNA-protein interplay, RNA-RNA base pairing and RNA-DNA base pairing [11]. Therefore, IncRNAs directly regulate gene expression on transcription, post transcription, and epigenetics level. Increasing reports suggested that lncRNAs, as a tumor regulator, were participated in complex network of biological regulation $[12,13]$. Increasing IncRNAs were reported as the markers in CRC diagnosis, such as MALAT1, HOTAIR, H19 and CCAT [14-17]. Long non-coding RNA RP11-708H21.4 was identified to be down-regulated in CRC. Low expression level of RP11-708H21.4 was correlated with bad prognosis. Moreover, overexpressed RP11-708H21.4 play a role of tumor suppressor, which could enhance the sensitivity of 5-FU to colon cells [18]. In this review, we summarized a hot topic functionand clinical application of IncRNAs which will be promising targets on diagnostics and therapy of CRC.

\section{Regulation effect of IncRNAs}

Similarly to mRNAs, IncRNAs has a construction with 5' cap and 3' ploy A, and its forming process is involved in complicated cleaving pattern [11]. Based on sites relative to the protein-coding genes, IncRNAs are classified as intergenic lncRNAs, intronic lncRNAs, bidirectional lncRNAs, sense lncRNAs and antisense lncRNAs to act as regulators in tumor pathology [10]. Firstly, as cis-acting element or trans-acting element, lncRNAs contribute to control gene transcription. Moreover, lncRNAs also interact with protein to exert its function in gene regulation. One of themost famous cis-acting element is lncRNAs X-inactivationspecifictranscript (Xist), which recruits polycomb repressive complex 2 (PRC2) leading to H3 acetylation and methylation, further inducing silence of whole X-chromosome $[19,20]$. Recent study showed that long intergenic noncoding RNA p21 (lincRNA-p21) mediated p53 downstream gene [21]. The regulation of lincRNA-p21 belonged to hnRNP-K protein dependent transcriptional silencing and play a negative role in hindering expression of p53 downstream gene [22]. LncRNAs p53-induced noncoding RNA (PINCR) is another IncRNAs to regulate a subset of p53 targets. Binding to Matrin3 protein, PINCR is involved in enhancer region of these genes [23].

In addition, lncRNAs could interact with microRNA (miRNA) to regulate gene expression [24]. As we known, miRNAs exerts its function via targeting 3' UTR of mRNA [25]. Increasing studies demonstrated that IncRNAs played important roles in the regulation of miRNA. MD et al. summarized the four way of IncRNAs interacting with miRNAs, including acting as host gene to miRNAs, being instability by miRNAs, competing mRNA with miRNAs, trapping miRNAs [24]. The first interaction is that lncRNAs could be as the precursor sequence for miRNA. Through PriMir analysis, many lncRNAs are detected as host gene for miRNAs, such as PVT1 $[26,27]$. Secondly, miRNAs could reduce the stability of lncRNAs. For example, Yoon et al. reported that let-7 family binded to RNA-binding protein (RBP) HuR for reducing the stability of long intergenic non-coding RNAs p21 [28]. Thirdly, IncRNAs is found to regulating the miRNAs expression to bind to miRNAs or its target. LncRNAs BACE1AS was reported to rob the target of miR-485-5p, BACE1, for relaxing the inhibition of BACE1 by miR-485-5p [29]. The last and common way is that lncRNAs, as competing endogenous RNAs (ceRNAs), play sponging roles to competitively bind to miRNAs for inhibiting binding activity. LncRNAs UCC could be interact with miR-143 by bioinformatics analysis, dual-luciferase reporter assays, and RNA immunoprecipitation, and UCC expression shows a negative relationship 
with miR-143 in CRC [30]. Particularly, H19 has been identified in many studies acts as a miRNA decoy to bind miRNA and inhibit its activities in CRC, such as miR-138, miR-200a and miR-675-5p [31-33]. Hence, interaction of IncRNAs and miRNAs provide a new prospect to deeply understand IncRNAs-induced reactions involved in the pathogenesis and pathology of CRC.

\section{Dysregulated IncRNAs in CRC}

As we known, cancer capacity show infinite multiplication, invasion and metastasis, especially CRC. However, mechanism of cancer is more complicated than we imagined. Recently, sequencing technique is applied to detect transcriptome of cancer tissues including miRNAs and lncRNAs [34]. Increasing evidences found presence of dysregulated lncRNAs in various types of cancer, such as hepatic carcinoma, lung carcinoma and colorectal carcinoma controlled with its adjacent tissues [35-37].

It has been definite that lncRNAs play double roles in CRC. Some lncRNAs are upregulated, which adverse to CRC development, while the others were down-regulated, which contribute to CRC development.

\section{The role of IncRNAs in CRC}

The process of normal cells transformed into tumor is growingly developed related to multistage reaction and mutation accumulation. In this course, cancerous cells are increasingly away from the control by its normal regulating mechanism, which endows some new capacity and become cancer cells [38]. With the increasing of lncRNAs studies, more and more dysregulated IncRNAs were involved in regulating tumor progression $[39,40]$.

H19 was located on human chromosome 11 and was reported as regulator on cell growth and development [41]. It was detected up-regulated expression in CRC tissues. Survival analyses showed a significant poor prognosis in CRC patients with high H19 expression. Through verification of functional experiment, H19 was found as an oncogene to promote CRC cell proliferation [14]. Insulin-like growth factor 2 gene (IGF2), a paternal imprinted gene, was uniformly located on human chromosome 11 [42]. Study reported that differentially methylated region (DMR), which was located on H19 promoter upstream, could regulate IGF2 imprinting by aberrant DNA methylation [43, 44]. The link of H19 and IGF2 could affect tumor crucial activity by promoting DNA replication and hypermethylation on epigenetics $[45,46]$. Recently, Lihua et al. found a novel IncRNAs, lnc34a, was notably upregulated in colon cancer stem cell (CCSC) lines and promoted CCSC self-renewing and tumorigenesis. Moreover, lnc34a recruit Dnmt3a via PHB2 and HDAC1 to target miR-34a by methylating and deacetylatingits promoter to promote CRC cell proliferation [47]. Upregulated GAS5 reduced ability of cell proliferation, and promoted G0/G1 cell cycle arrest and apoptosis [48]. As we known, cancer cells always show apoptosis resistance under a variety of stress environment, such as oxygen deficit, denutrition, antitumor therapy [49]. Therefore, it was the reason that cancer cells could be survived by autophagy to mediate intracellular recycle of energy and metabolite [50]. Moreover, lncRNAs were reported that played important roles in regulating autophagy in cancer [51]. As previously mentioned, lincPOU3F3 was an oncogene that silencing linc-POU3F3 inhibited proliferation and migration, induced apoptosis in CRC. SMAD4, which is involved in TGF- $\beta$-induced autophagy, showed an increase because of linc-POU3F3 knockdown $[52,53]$. In addition, autophagy related protein, BECLIN1, ATG5, ATG7, and LC3 II, were continually accumulated by linc-POU3F3 knockdown due to interdicted autophagy in CRC [53]. This study declared that linc-POU3F3 exerts its functional potential by mediating CRC autophagy. Recent study showed that dysregulated MEG3 also regulated tumor autophagy, tumorigenesis and progression, and further found that MEG3 had a negative related with an autophagy marker, microtubule-associated protein 1A/1B-light chain 3 (Atg8/LC3), Atg 3 [54]. Based on this, dysregulated MEG3 in CRC might induce autophagy by regulating autophagy key enzyme. 
Moreover, malignant tumor always showed tumor metastasis, which is depended on neovascularization. The angiogenesis is a key process for forming new vessels to offer a guiding for tumor cell from primary site to remote organs [55]. This process is multidimensional that vascular endothelial cell (VEC) differentiates from existing vasculaturs, migrates and forms new capillaries [55]. Tumor cell induces angiogenesis by liberating bioactive products to stimulate angiogenesis, such as vascular endothelial cell growth factor (VEGF), angiogenin (ANG), platelet derived growth factor (PDGF), transforming growth factor (TGF), fibroblast growth factors (FGF), which targeting VEC for increasing ability of proliferation. Then, variant VEC servesfor tumor cell progression [56]. Recently clinical evidences demonstrated that dysregulated lncRNAs were significantly correlated with lymph node metastasis, tumor differentiation and TNM stage, especially vascular invasion in CRC [57, 58]. Following increasing evidences verified that angiogenesis was regulated by lncRNAs.

With the development of bioinformatics, sequencing technique and bioinformatic analysesare used to find more dysregulated lncRNAs and explore its potential biological function. Through analyzing lncRNAs and its regulated mRNA in colon cancer tissues, the data showed that a interaction with IncRNAs and mRNAs was involved in cellular activity of cell division, angiogenesis, apoptotic, et al. [59]. LncRNAs maternally expressed gene 3 (MEG3) was located on human chromosome 14. Differential expression analysis showed a low MEG3 expression level in diverse tumor, including CRC, and overexpression of MEG3 could inhibit CRC cell proliferation both in vitro and in vivo $[54,60]$. Besides, increasing MEG3 expression not only restrained proliferation but also showed a negative effect on proliferation and angiogenesis in VEC. Through further study, MEG3 exerts its tumor suppression effect by playing a miRNA sponge to regulate miR-9 [61]. These studies above suggested that MEG3 might control double effect on inhibition of CRC proliferation by impeding angiogenesis in VEC.

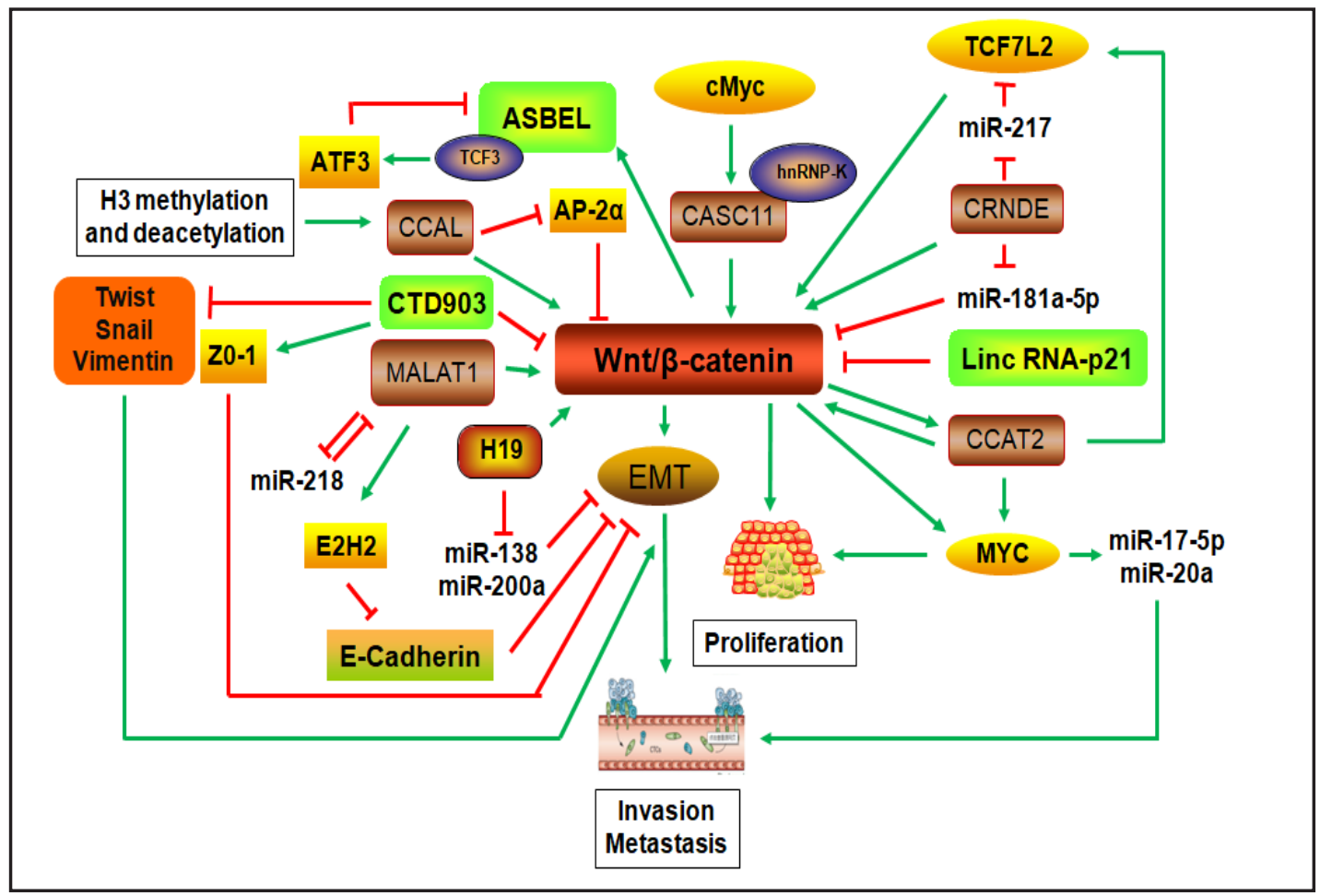

Fig. 1. Signalling pathway of p53 by lncRNAs. Red arrows represented inhibition of p53 pathways; Green arrows indicated promotion of p53 pathways. Red rectangles indicated onco-lncRNAs. Violetrectangles represented suppessor of IncRNAs. Red rectangles indicated oncogene of lncRNAs. Purplerectangles indicated tumor suppressor of IncRNAs. 
In addition, IncRNAs might be involved in certain molecular pathway to exert its regulation in CRC progression.

\section{P53 signalling pathway}

P53 was reported as a recognized tumor suppressor on inducing cell cycle arrest, apoptosis and other tumor behavior [62]. Cell cycle is one of essential feature in normal cells. However, tumor cells show inordinate cell cycle and this specific features offer unlimited reproduction to accelerate tumorigenesis and progression, which was involved in p53 regulatory mechanism $[63,64]$. Some abnormal regulators, contain passionately reported lncRNAs, are the key to comprehend mechanism of tumorigenesis and progression (Fig. 1).

LncRNAs reprogramming (ROR) was reported as oncogene to facilitate CRC proliferation [65]. The deficiency of IncRNAs-ROR led to inhibition of cell proliferation, enhancement of cell apoptosis and motivation of cell cycle arrest in G0/G1 phase. There are increasing expressions of p53, p21 and FAS protein by downregulating lncRNAs-ROR in CRC. These findings suggested that lncRNAs-ROR played a tumor promoter by inhibiting p53 signaling way in CRC. Moreover, lncRNAs-ROR was reported as p53 upstream gene. Upregulated lncRNAs-ROR could weak radiosensitivity of CRC cells via sponging miR-145 and impeding p53 translation, play an inhibited role in radiotherapy effect to CRC [66].

\section{Wnt/ $\beta$-catenin signalling pathway}

Wnt/ $\beta$-catenin is a signaling involved in tumor development [67]. EMT, as a process of cell-cell adhesion, promotes tumor invasion and metastasis [68]. Among this pathway, $\beta$-catenin, which is a pivotal initial protein of Wnt signaling, is combined with E-cadherin to

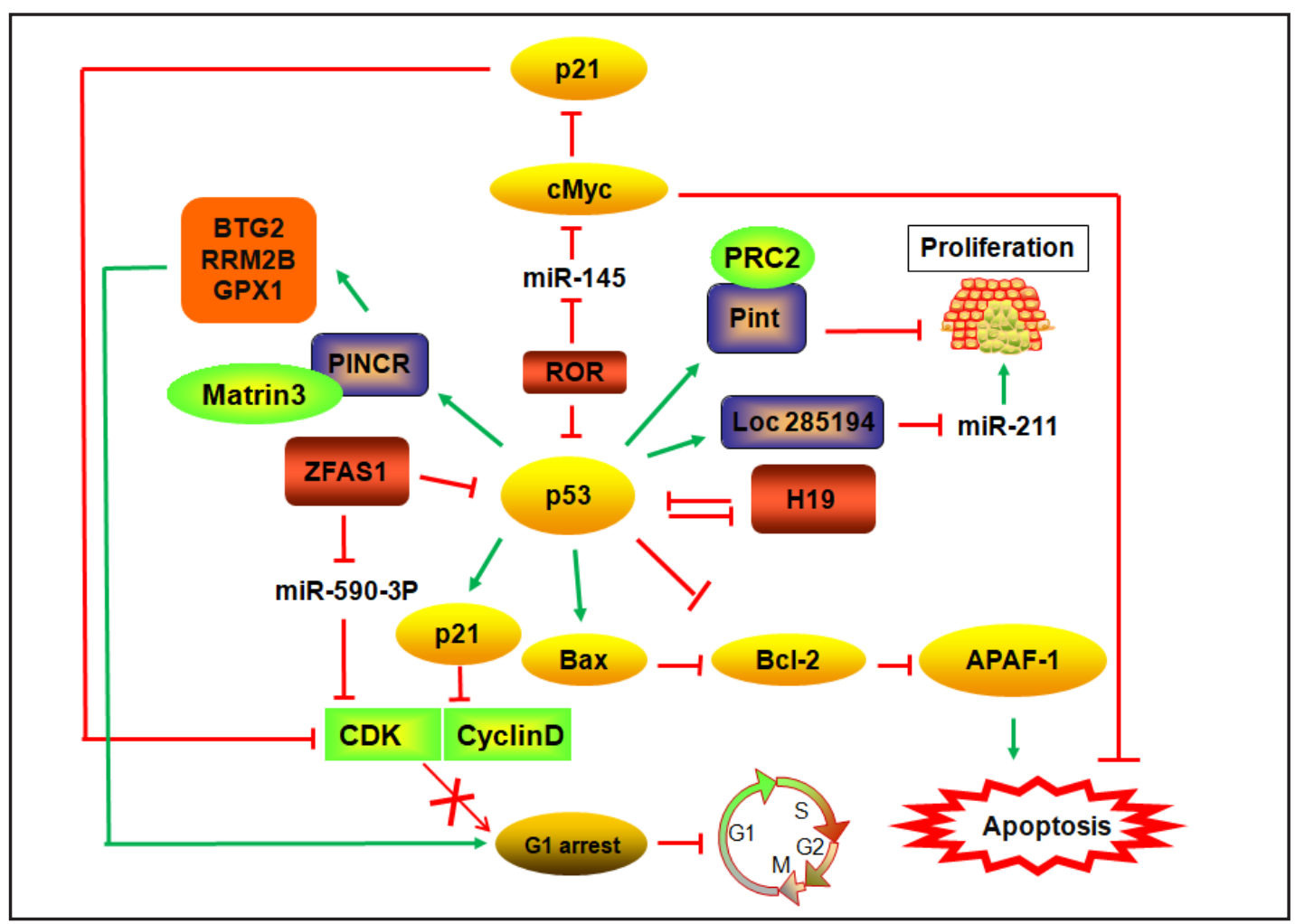

Fig. 2. Signalling pathway of $\mathrm{Wnt} / \beta$-catenin by lncRNAs. Red arrows represented inhibition of Wnt/ $\beta$ catenin pathways; Green arrows indicated promotion of Wnt/ $\beta$-catenin pathways. Brownrectangles represented oncogene of IncRNAs. Green rectangles represented tumor suppessor of lncRNAs. 
be as cytoskeletal protein effecting on cell motility $[69,70]$. CTD903 was reported as a tumor suppressor that inhibited EMT phenotypes and CRC cell metastasis. After downregulating CTD903 expression, Wnt/ $\beta$-catenin expression, EMT-related protein expression (Vimentin, epithelialmarker Z0-1) and its upstream transcriptional factors (Twist, Snail) were inhibited in CRC cell [71]. Differently, long non-coding RNA CCAL played an oncogenic role to CRC cell progression. Methylation and deacetylases of $\mathrm{H} 3$ provoked upregulated CCAL, further suppressing activator protein $2 \alpha(\mathrm{AP}-2 \alpha)$, subsequently activated Wnt/ $\beta$-catenin signalling pathway. Specifically speaking, that overexpression of CCAL reduce AP- $2 \alpha$ expression and induce expression of $\beta$-catenin to target $c$-myc, cyclin D1 and E-cadherin. Besides, activation of Wnt/ $\beta$-catenin signalling pathway decreased MDR1/P-glycoprotein expression to involve inmechanism of CCAL on regulating CRC cell progression [72].

In addition to regulation of IncRNAs-protein, some miRNAs are contributed to mechanism of IncRNAs by Wnt/ $\beta$-catenin signaling pathway. LncRNAs CRNDE was reported in regulating CRC proliferation and migration of tumors by mediating Wnt/ $\beta$-catenin signaling, and as a ceRNA to bind to miR-217. Transcription factor 7-like 2 (TCF7L2) was the target of miR-217. CRNDE could competitively bind to miR-217 to increase TCF7L2 expression for activating Wnt/ $\beta$-catenin signaling. Moreover, CRNDE directly interacted with TCF7L2 to activate $W n t / \beta$-catenin signaling. Based on this study, CRNDE showed double effects on regulation of Wnt/ $\beta$-catenin signaling pathway [73]. Similarly, CCAT2 showed a tumor-promoting role on cancer growth, metastasis and chromosomal instability by interacting with TCF7L2 to regulate Wnt target genes. In turn, CCAT2 is reversely regulated by Wnt/ $\beta$-catenin signaling pathway due to regulation position of CCAT2 on Wnt downstream, which implied that there is a loop between CCAT2 and Wnt [74]. There were many reported lncRNAs involved in Wnt/ $\beta$-catenin signaling pathway (Fig. 2).

\section{Other signalling pathways}

RP11-708H21.4 was a novel low expressed lncRNAs in CRC. Overexpression of lncRNAs RP11-708H21.4 suppressed CRC cell proliferation through induction of G1 arrest and apoptosis, inhibition of CRC cell invasion. Through decreasing phosphorylation of AKT, mTOR, as well as S6K1, RP11-708H21.4 hindered AKT/mTOR pathway in CRC cells [18]. Linc-POU3F3 was a novel biotarget in CRC, and knockdown linc-POU3F3 inhibited cell proliferation, migration and invasion in CRC cell lines, and promoted apoptosis by inducing G1 cell cycle arrest through change expression of cyclin D1, CDK4, p18, Rb, and phosphorylated $\mathrm{Rb}$. SMAD4 was a key factor in BMP pathway, which influenced capacity of tumor metastasis. Silencing linc-POU3F3 led to increasing of SMAD4 and pSMAD1 expression to weak migration and invasion of CRC [53].

\section{Clinical significance of IncRNAs for CRC}

Increasing studies concentrated on diagnostic and therapeutic roles of IncRNAs in cancer. Ectopic lncRNAs always show a tissue and cancer specificity [75]. MALAT1, HOTAIR, H19 and CCAT family were reported as the markers in CRC diagnosis. H19 and HOTAIR was up-regulated, which implied a poor prognosis of high expression in CRC $[14,15]$. The results of clinical features showed that $\mathrm{H} 19$ was associated with TNM-stage, tumour differentiation, HOTAIR with TNM-stage, tumour differentiation vessel invasion. Similarly, the FOXP4AS1and HOXA-AS2 showed onco-role in promoting CRC proliferation and apoptosis $[16,17]$. These evidences displayed unfavourable prognostic markers for CRC patients. Oppositely, TUSC7 and GAS5 were downregulated and suggested a better prognosis of high expression level in CRC. The results of clinical features showed that TUSC7 was associated with tumor size, HOTAIR with tumor size and TNM-stage. In table 1, we concluded a correlation with CRC clinical features and lncRNAs for visually understanding that lncRNAs might be as markers for CRC diagnosis (Table 1) [16, 17, 47, 57, 75-80]. Sun et al. reported that ANRIL could enhance cell mobility and invasion by in-vitro tube formation HLECs invasion. When ANRIL were 


\begin{tabular}{|c|c|c|}
\hline \multirow{2}{*}{$\begin{array}{l}\text { Cellular Physiology } \\
\text { and Biochemistry }\end{array}$} & \multicolumn{2}{|c|}{ Cell Physiol Biochem 2018;46:431-441 } \\
\hline & $\begin{array}{l}\text { DOI: 10.1159/000488610 } \\
\text { ر Published online: April 03, } 2018\end{array}$ & $\begin{array}{l}\text { O } 2018 \text { The Author(s). Published by S. Karger AG, Basel } \\
\text { www.karger.com/cpb }\end{array}$ \\
\hline
\end{tabular}

Table 1. The expression and clinical characteristics of lncRNAs in CRC

\begin{tabular}{|c|c|c|c|c|c|c|c|c|c|c|}
\hline \multirow[b]{2}{*}{ LncRNAs } & \multirow{2}{*}{$\begin{array}{c}\text { Chromosal } \\
\text { location }\end{array}$} & \multirow[b]{2}{*}{ Gene types } & \multirow[b]{2}{*}{ Potential clinical significant } & \multicolumn{7}{|c|}{ CRC patient clinicopathologic features } \\
\hline & & & & $\begin{array}{l}\text { Tumor } \\
\text { size }\end{array}$ & $\begin{array}{l}\text { Tumour } \\
\text { differentiation }\end{array}$ & TNM-stage & $\begin{array}{l}\text { Lymphatic } \\
\text { metastasis }\end{array}$ & $\begin{array}{l}\text { Distant } \\
\text { metastasis }\end{array}$ & $\begin{array}{l}\text { Vessel } \\
\text { invasion }\end{array}$ & References \\
\hline H19 & $11 \mathrm{p} 15.5$ & Oncogene & Tumor growth & I & * & * & I & I & I & [75] \\
\hline HOTAIR & $12 \mathrm{q} 13.13$ & Oncogene & Metastasis and EMT & I & ** & ** & I & I & * & [57] \\
\hline DANCR & $4 \mathrm{q} 12$ & Oncogene & Invasion and migration & 1 & 1 & * & * & I & ' & [76] \\
\hline CRNDE & $16 \mathrm{q} 12.2$ & Oncogene & $\begin{array}{l}\text { Proliferation and } \\
\text { chemoresistance }\end{array}$ & $* *$ & / & / & $*$ & / & / & [77] \\
\hline FOXP4-AS1 & $6 \mathrm{p} 21.1$ & Oncogene & Proliferation and apoptosis & * & / & $*$ & l & / & / & [16] \\
\hline HOXA-AS2 & $7 \mathrm{p} 15.2$ & Oncogene & Proliferation and apoptosis & $* *$ & I & ** & ** & I & 1 & [17] \\
\hline NNT-AS1 & $5 \mathrm{p} 12$ & Oncogene & Proliferation and migration & / & $*$ & $* *$ & $* *$ & I & $* *$ & [78] \\
\hline TUSC7 & $3 q 13.31$ & $\begin{array}{c}\text { Tumor } \\
\text { suppressor }\end{array}$ & Proliferation & $*$ & / & / & / & / & / & [79] \\
\hline GAS5 & $1 \mathrm{q} 25.1$ & $\begin{array}{c}\text { Tumor } \\
\text { suppressor }\end{array}$ & $\begin{array}{c}\text { Proliferation, G0/G1 arrest } \\
\text { and apoptosis }\end{array}$ & $* *$ & / & $*$ & l & I & / & [47] \\
\hline ANRIL & $9 \mathrm{p} 21.3$ & Oncogene & $\begin{array}{l}\text { Lymphangiogenesis and } \\
\text { lymphatic metastasis }\end{array}$ & I & I & * & * & I & / & [80] \\
\hline
\end{tabular}

downregulated by geneinterference, it is significant results that the rate of tumor growth and lymphatic metastasis and the frequency of transferred lymph nodes were reduced in vivo. Downregulated RP11-708H21.4 showed a correlation with poor prognosis, which artificial overexpressed RP11-708H21.4 could enhance the sensitivity of 5-FU to colon cells [18]. Currently, RNA interference (RNAi) technology was extensive to explore the function of gene. But, it still was limited due to its unknown side effect and stability to human. Does it induce other gene expression change? More animal experiment and clinical research need to be proved. Moreover, the upregulated lncRNA is more difficult than downregulated lncRNA expression due to less method, which implied a serious problem for tumor suppressor. Special chemical modification or stable vector was needed.

Recently, exosome is identified to transfer noncoding RNA for cancer diagnosis [82]. With thediscovery of exosome, the IncRNA-faced dilemma was broken. RNA-Seq was used to identified transcriptome and long noncoding RNA sequencing from three extracellular vesicle subtypes in colon cancer LIM1863 cell line. 2, 389 mRNAs, 317 pseudogene transcripts, 1, 028 lncRNAs and 206 short non-coding RNAs were found in the exosomes released by LIM1863, which implied that the IncRNA is very enriched in LIM1863-excretive exosomes [83]. Moreover, Exosomal CRNDE-h is identified and stable in serum of CRC patients. High expression CRNDE-h was correlated lymph node metastasis $(\mathrm{P}=0.019)$ and distant metastasis $(\mathrm{P}=0.003)$ of CRC patients and has a lower overall survival rates $(34.6 \%$ vs. $68.2 \%, \mathrm{P}<0.001$ ) [84]. Therefore, IncRNA still has a potential in CRC diagnosis and therapy.

\section{Conclusion}

Recently, researchers try their best to find pathogenesis and nosetiology of CRC. With the development of bioinformatics, IncRNAs catched much attentions of numerous researchers and the landscape of IncRNAs functions were found in course of tumor development. To data, increasing number of lncRNAs had been reported that contributed to complex regulation network of development in CRC and showed potential role in CRC diagnosis and treatment. In this review, we summarized function and mechanism of IncRNAs involved in CRC progression, which will deep the understanding of lncRNAs regulation for further being a promising biomarkers and therapeutic targets for CRC patients.

\section{Acknowledgements}

This study was supported by the National Natural Science Foundation of China (81560385), the Medical Scientific and Technological Research Project of Henan Province (201702027), Youth Innovation Fund Project of The First Affiliated Hospital of Zhengzhou University (YNQN2017035), and the China Postdoctoral Science Foundation (2017M610462). 


\section{Cellular Physiology Cell Physiol Biochem 2018;46:431-441 \begin{tabular}{c|c} 
DOI: 10.1159/000488610 & O 2018 The Author(s). Published by S. Karger AG, Basel \\
www.karger.com/cpb
\end{tabular}}

Sun et al.: Long Noncoding RNAs in Colorectal Cancer

\section{Disclosure Statement}

All authors have claimed that there is no existing conflict.

\section{References}

1 Ferlay J, Soerjomataram I, Dikshit R, Eser S, Mathers C, Rebelo M, Parkin DM, Forman D, Bray F: Cancer incidence and mortality worldwide: Sources, methods and major patterns in GLOBOCAN 2012. Int J Cancer 2015;136: E359-386.

-2 Chen WQ, Zheng RS, Baade PD, Zhang SW, Zeng HM, Bray F, Jemal A, Yu XQ, He J: Cancer Statistics in China, 2015. CA Cancer J Clin 2016;66:115-132.

-3 Zhu JZ, Tan ZQ Hollis-Hansen K, Zhang Y, Yu CH, Li YM: Epidemiological Trends in Colorectal Cancer in China: An Ecological Study. Digest Dis Sci 2017;62:235-243.

4 Miller KD, Siegel RL, Lin CC, Mariotto AB, Kramer JL, Rowland JH, Stein KD, Alteri R, Jemal A: Cancer treatment and survivorship statistics, 2016. CA Cancer J Clin 2016;66: 271-289.

5 Li H, Ma SQ, Huang J, Chen XP, Zhou HH: Roles of long noncoding RNAs in colorectal cancer metastasis. Oncotarget 2017; 8:39859-39876

6 Weng M, Wu D, Yang C, Peng H, Wang G, Wang T, Li X: Noncoding RNAs in the development, diagnosis, and prognosis of colorectal cancer. Transl Res 2016; 181:108-120

7 Alexander RP, Fang G, Rozowsky J, Snyder M, Gerstein MB: Annotating non-coding regions of the genome. Nat Rev Genet 2010; 11:559-571.

-8 Carninci P, Kasukawa T, Katayama S, Gough J, Frith MC, Maeda N, Oyama R, Ravasi T, Lenhard B, Wells C: The transcriptional landscape of the mammalian genome. Science 2005;309:1559-1563.

-9 Shi X, Sun M, Liu H, Yao Y, Song Y: Long non-coding RNAs: a new frontier in the study of human diseases. Cancer Lett 2013;339:159-166.

10 Jia H, Osak M, Bogu GK, Stanton LW, Johnson R, Lipovich L: Genome-wide computational identification and manual annotation of human long noncoding RNA genes. RNA 2010;16:1478-1487.

-11 Derrien T, Johnson R, Bussotti G, Tanzer A, Djebali S, Tilgner H, Guernec G, Martin D, Merkel A, Knowles DG: The GENCODE v7 catalog of human long noncoding RNAs: analysis of their gene structure, evolution, and expression. Genome Res 2012; 22:1775-1789

12 Gibb EA, Brown CJ, Lam WL: The functional role of long non-coding RNA in human carcinomas. Mol Cancer 2011;10:38.

13 Zhang H, Chen Z, Wang X, Huang Z, He Z, Chen Y: Long non-coding RNA: a new player in cancer. J Hematol Oncol 2013;6:37.

14 Dong H, Xu G, Meng W, Yu Q, Xu Y, Jing Y, Dong N, He J, Qian S, Lv G: Long noncoding RNA H19 indicates a poor prognosis of colorectal cancer and promotes tumor growth by recruiting and binding to eIF4A3. Oncotarget 2016;7:22159-22173.

15 Luo ZF, Zhao D, Li XQ Cui YX, Ma N, Lu CX, Liu MY, Zhou Y: Clinical significance of HOTAIR expression in colon cancer. World J Gastroenterol 2016;22:5254-5259.

-16 Li J, Lian Y, Yan C, Cai Z, Ding J, Ma Z, Peng P, Wang K: Long non-coding RNA FOXP4-AS1 is an unfavourable prognostic factor and regulates proliferation and apoptosis in colorectal cancer. Cell Prolif 2016; 50:e12312

17 Ding J, Xie M, Lian Y, Zhu Y, Peng P, Wang J, Wang L, Wang K: Long noncoding RNA HOXA-AS2 represses P21 and KLF2 expression transcription by binding with EZH2, LSD1 in colorectal cancer. Oncogenesis 2017;6:e288.

18 Sun L, Jiang C, Xu C, Xue H, Zhou H, Gu L, Liu Y, Xu Q: Down-regulation of long non-coding RNA RP11$708 \mathrm{H} 21.4$ is associated with poor prognosis for colorectal cancer and promotes tumorigenesis through regulating AKT/mTOR pathway. Oncotarget 2017;8:27929-27942.

19 Pollex T, Heard E: Recent advances in X-chromosome inactivation research. Curr Opin Cell Biol 2012;24:825-832.

20 Hall LL, Lawrence JB: XIST RNA and architecture of the inactive X chromosome: implications for the repeat genome. Cold Spring Harb Symp Quant Biol 2010;75: 345-356. 


\section{Cellular Physiology Cell Physiol Biochem 2018;46:431-441

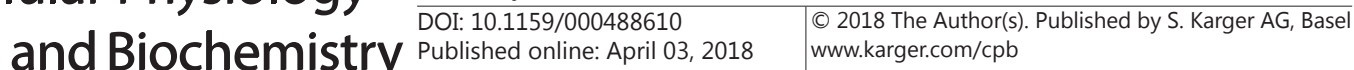

Sun et al.: Long Noncoding RNAs in Colorectal Cancer

21 Chen S, Liang H, Yang H, Zhou K, Xu L, Liu J, Lai B, Song L, Luo H, Peng J: LincRNa-p21: function and mechanism in cancer. Med Oncol 2017;34:98.

-22 Huarte M, Guttman M, Feldser D, Garber M, Koziol MJ, Kenzelmannbroz D, Khalil AM, Zuk O, Amit I, Rabani M: A large intergenic noncoding RNA induced by p53 mediates global gene repression in the p53 response. Cell 2010;142:409-419.

23 Chaudhary R, Gryder B, Woods WS, Subramanian M, Jones MF, Li XL, Jenkins LM, Shabalina SA, Mo M, Dasso M: Prosurvival long noncoding RNA PINCR regulates a subset of p53 targets in human colorectal cancer cells by binding to Matrin 3. Elife 2017;6:e23244.

-24 Ballantyne MD, Mcdonald RA, Baker AH: LncRNA/microRNA interactions in the vasculature. Clin Pharmacol Ther 2016;99:494-501.

25 Ambros V: microRNAs: tiny regulators with great potential. Cell 2001;107:823-826.

-26 Alvarez ML, Khosroheidari M, Eddy E, Kiefer J: Role of microRNA 1207-5P and its host gene, the long noncoding RNA Pvt1, as mediators of extracellular matrix accumulation in the kidney: implications for diabetic nephropathy. Plos One 2013;8:e77468.

27 He S, Su H, Liu C, Skogerbø G, He H, He D, Zhu X, Liu T, Zhao Y, Chen R: MicroRNA-encoding long non-coding RNAs. BMC Genomics 2008;9:1-11.

28 Yoon JH, Abdelmohsen K, Srikantan S, Yang X, Martindale J, De S, Huarte M, Zhan M, Becker K, Gorospe M: LincRNA-p21 Suppresses Target mRNA Translation. Mol Cell 2012;47:648-655.

29 Faghihi MA, Zhang M, Huang J, Modarresi F, Brug MPVD, Nalls MA, Cookson MR, St-Laurent G, Wahlestedt C: Evidence for natural antisense transcript-mediated inhibition of microRNA function. Genome Biol 2010;11:R56.

30 Huang FT, Chen WY, Gu ZQ, Zhuang YY, Li CQ, Wang LY, Peng JF, Zhu Z, Luo X, Li YH: The novel long intergenic noncoding RNA UCC promotes colorectal cancer progression by sponging miR-143 Cell Death Dis 2017;8:e2778.

31 Yang Q Wang X, Tang C, Chen X, He J: H19 promotes the migration and invasion of colon cancer by sponging miR-138 to upregulate the expression of HMGA1. Int J Oncol 2017;50: 1801-1809.

-32 Yang W, Ning N, Jin X: The lncRNA H19 Promotes Cell Proliferation by Competitively Binding to miR-200a and Derepressing $\beta$-Catenin Expression in Colorectal Cancer. Biomed Res Int 2017;2017:1-8.

-33 Chen S, Bu D, Ma Y, Zhu J, Chen G, Sun L, Zuo S, Li T, Pan Y, Wang X: H19 Overexpression Induces Resistance to 1, 25(OH)2D3 by Targeting VDR Through miR-675-5p in Colon Cancer Cells. Neoplasia 2017;19:226236.

34 Li Q Dai Y, Wang F, Hou S: Differentially expressed long non-coding RNAs and the prognostic potential in colorectal cancer. Neoplasma 2016;63:977-983

-35 Zhang Q, Matsuura K, Kleiner DE, Zamboni F, Alter HJ, Farci P: Analysis of long noncoding RNA expression in hepatocellular carcinoma of different viral etiology. J Transl Med 2016;14:328.

-36 Li W, Chen Z, Li A, Wang Y, Zhang Z, Guo Y, Liu C: Analysis of Long Non-Coding RNA Expression Profiles in Non-Small Cell Lung Cancer. Cell Physiol Biochem 2016;38:2389-2400.

-37 Jing F, Jin H, Mao Y, Li Y, Ding Y, Fan C, Chen K: Genome-wide analysis of long non-coding RNA expression and function in colorectal cancer. Tumour Biol 2017;39:1010428317703650.

-38 Schwitalla S, Fingerle AA, Cammareri P, Nebelsiek T, Göktuna SI, Ziegler PK, Canli O, Heijmans J, Huels DJ, Moreaux G: Intestinal tumorigenesis initiated by dedifferentiation and acquisition of stem-cell-like properties. Cell 2013;152:25-38.

-39 Batista PJ, Chang HY: Long Noncoding RNAs: Cellular Address Codes in Development and Disease. Cell 2013;152:1298-1307.

40 Kim HJ, Eoh KJ, Kim LK, Nam EJ, Yoon SO, Kim KH, Lee JK, Kim SW, Kim YT: The long noncoding RNA HOXA11 antisense induces tumor progression and stemness maintenance in cervical cancer. Oncotarget 2016;7:83001-83016.

41 Gabory A, Jammes H, Dandolo L: The H19 locus: Role of an imprinted non-coding RNA in growth and development. Bioessays 2010;32:473-480.

42 Arney KL: H19 and Igf2--enhancing the confusion? Trends Genet 2003;19:17-23.

-43 Engemann S, Strödicke M, Paulsen M, Franck O, Reinhardt R, Lane N, Reik W, Walter J: Sequence and functional comparison in the Beckwith-Wiedemann region: implications for a novel imprinting centre and extended imprinting. Hum Mol Genet 2000;9:2691-2706. 


\section{Cellular Physiology Cell Physiol Biochem 2018;46:431-441

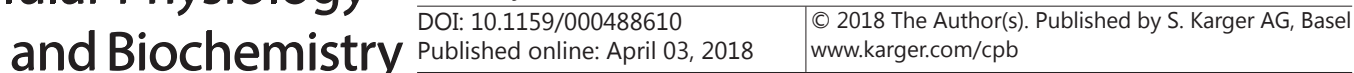

Sun et al.: Long Noncoding RNAs in Colorectal Cancer

44 Leroith D, Jr CR: The insulin-like growth factor system and cancer. Cancer Lett 2003;195:127-137.

45 Zhong H, Fazenbaker C, Chen C, Breen S, Huang J, Yao X, Ren P, Yao Y, Herbst R, Hollingsworth RE: Overproduction of IGF-2 drives a subset of colorectal cancer cells, which specifically respond to an anti-IGF therapeutic antibody and combination therapies. Oncogene 2016;36:797-806.

-46 Sachdev D, Yee D: Disrupting insulin-like growth factor signaling as a potential cancer therapy. Mol Cancer Ther 2007;6:1-12.

47 Wang L, Bu P, Ai Y, Srinivasan T, Chen HJ, Xiang K, Lipkin SM, Shen X: A long non-coding RNA targets microRNA miR-34a to regulate colon cancer stem cell asymmetric division. Elife 2016;5:e14620

-48 Yang Y, Shen Z, Yan Y, Wang B, Zhang J, Shen C, Li T, Ye C, Gao Z, Peng G: Long non-coding RNA GAS5 inhibits cell proliferation, induces G0/G1 arrest and apoptosis, and functions as a prognostic marker in colorectal cancer. Oncol Lett 2017;13:3151-3158.

49 ME L, E A, D G, A L: ROS-mediated Autophagy Defines the Fate of Cancer Stem Cells. Antioxid Redox Signal DOI: 10.1089 /ars.2017.7223.

50 Guo JY, Xia B, White E: Autophagy-mediated tumor promotion. Cell 2013;155:1216-1219.

51 Ying L, Huang Y, Chen H, Wang Y, Xia L, Chen Y, Liu Y, Qiu F: Downregulated MEG3 activates autophagy and increases cell proliferation in bladder cancer. Mol Biosyst 2013;9:407-411.

52 Lan SH, Wu SY, Zuchini R, Lin XZ, Su IJ, Tsai TF, Lin YJ, Wu CT, Liu HS: Autophagy-preferential degradation of MIR224 participates in hepatocellular carcinoma tumorigenesis. Autophagy 2014;10:1687-1689.

53 Shan TD, Xu JH, Yu T, Li JY, Zhao LN, Ouyang H, Luo S, Lu XJ, Huang CZ, Lan QS: Knockdown of linc-POU3F3 suppresses the proliferation, apoptosis, and migration resistance of colorectal cancer. Oncotarget 2016;7:961-975.

54 Xiu YL, Sun KX, Chen X, Chen S, Zhao Y, Guo QG, Zong ZH: Upregulation of the lncRNA Meg3 induces autophagy to inhibit tumorigenesis and progression of epithelial ovarian carcinoma by regulating activity of ATG3. Oncotarget 2017;8:31714-31725.

-55 Markowska A, Sajdak S, Markowska J, Huczyński A: Angiogenesis and cancer stem cells: New perspectives on therapy of ovarian cancer. Eur J Med Chem 2017;142:87-94

-56 De Palma M, Biziato D, Petrova TV: Microenvironmental regulation of tumour angiogenesis. Nat Rev Cancer 2017; 17:457-474.

57 Zhai H, Fesler A, Schee K, Fodstad O, Flatmark K, Ju J: Clinical significance of long intergenic noncoding RNA-p21 in colorectal cancer. Clin Colorectal Cancer 2013;12:261-266.

58 Wu ZH, Wang XL, Tang HM, Jiang T, Chen J, Lu S, Qiu GQ, Peng ZH, Yan DW: Long non-coding RNA HOTAIR is a powerful predictor of metastasis and poor prognosis and is associated with epithelial-mesenchymal transition in colon cancer. Oncol Rep 2014;32:395-402.

59 Li Q Li N, Lao Y, Lin W, Jiang G, Wei N, Wang C, Liu K, Wu J: Variable Levels of Long Noncoding RNA Expression in DNA Mismatch Repair-Proficient Early-Stage Colon Cancer. Dig Dis Sci 2017; 62:1235-1245.

60 Yin DD, Liu ZJ, Zhang E, Kong R, Zhang ZH, Guo RH: Decreased expression of long noncoding RNA MEG3 affects cell proliferation and predicts a poor prognosis in patients with colorectal cancer. Tumour Biol 2015;36:4851-4859.

-61 He C, Yang W, Yang J, Ding J, Li S, Wu H, Zhou F, Jiang Y, Teng L: Long Noncoding RNA MEG3 Negatively Regulates Proliferation and Angiogenesis in Vascular Endothelial Cells. DNA Cell Biol 2017;36:475-481.

62 Bradner JE: Cancer: An essential passenger with p53. Nature 2015;520:626.

-63 Lazo PA: Reverting p53 activation after recovery of cellular stress to resume with cell cycle progression. Cell Signal 2017;33:49-58.

64 Sharma G, Rana NK, Singh P, Dubey P, Pandey DS, Koch B: p53 dependent apoptosis and cell cycle delay induced by heteroleptic complexes in human cervical cancer cells. Biomed Pharmacother 2017;88:218231.

65 Hong L, Jiang X, Niu X: Long Non-Coding RNA Reprogramming (ROR) Promotes Cell Proliferation in Colorectal Cancer via Affecting P53. Med Sci Monit 2017;23:919-928.

66 Yang P, Yang Y, An W, Xu J, Zhang G, Jie J, Zhang Q: The long noncoding RNA-ROR promotes the resistance of radiotherapy for human colorectal cancer cells by targeting the p53/miR-145 pathway. J Gastroenterol Hepatol 2016;32:837-845.

67 El WA, Lalli E: The Wnt/beta-catenin pathway in adrenocortical development and cancer. Mol Cell Endocrino 2011;332:32-37. 


\section{Cellular Physiology Cell Physiol Biochem 2018;46:431-441 and Biochemistry Published online:April 03, $2018 \quad \begin{aligned} & \text { DOI 10159/2018 The Author(s). Published by S. Karger AG, Basel } \\ & \text { www.karger.com/cpb }\end{aligned}$ \\ Sun et al.: Long Noncoding RNAs in Colorectal Cancer}

68 Thiery JP, Acloque H, Huang RY, Nieto MA: Epithelial-mesenchymal transitions in development and disease. Cell 2009; 139:871-90.

69 Ghahhari NM, Babashah S: Interplay between microRNAs and WNT/ $\beta$-catenin signalling pathway regulates epithelial-mesenchymal transition in cancer. Eur J Cancer 2015;51:1638-1649.

-70 Guo YH, Wang LQ Li B, Xu H, Yang JH, Zheng LS, Yu P, Zhou AD, Zhang Y, Xie SJ: Wnt/ $\beta$-catenin pathway transactivates microRNA-150 that promotes EMT of colorectal cancer cells by suppressing CREB signaling. Oncotarget 2016; 7: 42513-42526.

71 Yuan Z, Yu X, Ni B, Chen D, Yang Z, Huang J, Wang J, Wang L: Overexpression of long non-coding RNACTD903 inhibits colorectal cancer invasion and migration by repressing Wnt/ $\beta$-catenin signaling and predicts favorable prognosis. Int J Oncol 2016;48:2675-2685.

72 Ma Y, Yang Y, Wang F, Moyer MP, Wei Q Zhang P, Yang Z, Liu W, Zhang H, Chen N: Long non-coding RNA CCAL regulates colorectal cancer progression by activating Wnt/ $\beta$-catenin signalling pathway via suppression of activator protein $2 \alpha$. Gut 2016;65:1494-1504.

73 Bo Y, Xuan Y, Du Q, Zhu B, Zhai Q, Li XX: The Long Non-Coding RNA CRNDE Promotes Colorectal Carcinoma Progression by Competitively Binding miR-217 with TCF7L2 and Enhancing the Wnt/ $\beta$-Catenin Signaling Pathway. Cell Physiol Biochem 2017;41:2489-2502.

74 Ling H, Spizzo R, Atlasi Y, Nicoloso M, Shimizu M, Redis RS, Nishida N, Gafà R, Song J, Guo Z: CCAT2, a novel noncoding RNA mapping to 8q24, underlies metastatic progression and chromosomal instability in colon cancer. Genome Res 2013;23:1446-1461.

75 Prensner JR, Chinnaiyan AM: The emergence of lncRNAs in cancer biology. Cancer Discov 2011;1:391-407.

76 Han D, Gao X, Wang M, Qiao Y, Xu Y, Yang J, Dong N, He J, Sun Q, Lv G: Long noncoding RNA H19 indicates a poor prognosis of colorectal cancer and promotes tumor growth by recruiting and binding to eIF4A3. Oncotarget 2016;7:22159-22173.

-77 Yang ZY, Yang F, Zhang YL, Liu B, Wang M, Hong X, Yu Y, Zhou YH, Zeng H: LncRNA-ANCR down-regulation suppresses invasion and migration of colorectal cancer cells by regulating EZH2 expression. Cancer Biomark 2017;18:95-104.

78 Han P, Li JW, Zhang BM, Lv JC, Li YM, Gu XY, Yu ZW, Jia YH, Bai XF, Li L: The lncRNA CRNDE promotes colorectal cancer cell proliferation and chemoresistance via miR-181a-5p-mediated regulation of Wnt/ $\beta$ catenin signaling. Mol Cancer 2017;16:9.

79 Wang Q, Yang L, Hu X, Jiang Y, Hu Y, Liu Z, Liu J, Wen T, Ma Y, An G: Upregulated NNT-AS1, a long noncoding RNA, contributes to proliferation and migration of colorectal cancer cells in vitro and in vivo. Oncotarget 2017;8:3441-3453.

80 Xu J, Zhang R, Zhao J: The Novel Long Noncoding RNA TUSC7 Inhibits Proliferation by Sponging MiR-211 in Colorectal Cancer. Cell Physiol Biochem 2017;41:635-644.

81 Sun ZQ Ou CL, Ren WG, Xie X, Li X, Li GY: Downregulation of long non-coding RNA ANRIL suppresses lymphangiogenesis and lymphatic metastasis in colorectal cancer. Oncotarget 2016;7:47536-47555.

82 Rabinowits G, Gerçel-Taylor C, Day JM, Taylor DD, Kloecker GH: Exosomal microRNA: a diagnostic marker for lung cancer. Clin Lung Cancer 2009; 10:42-46.

-83 Chen M, Xu R, Hong J, Greening DW, Rai A, Izumikawa K, Ishikawa H, Takahashi N, Simpson RJ: Transcriptome and long noncoding RNA sequencing of three extracellular vesicle subtypes released from the human colon cancer LIM1863 cell line. Sci Rep 2016;6:38397.

84 Liu T, Zhang X, Gao S, Jing F, Yang Y, Du L, Zheng G, Li P, Li C, Wang C: Exosomal long noncoding RNA CRNDE-h as a novel serum-based biomarker for diagnosis and prognosis of colorectal cancer. Oncotarget 2016;7:85551-85563. 